\title{
Attentional capture by globally defined objects
}

\author{
ROBERT RAUSCHENBERGER and STEVEN YANTIS \\ Johns Hopkins University, Baltimore, Maryland
}

\begin{abstract}
The abrupt appearance of a new perceptual object in the visual field typically captures visual attention. However, if attention is focused in advance on a different location, onsets can fail to capture attention (Yantis \& Jonides, 1990). In the present experiments, we investigated the extent to which the deployment of attention to the local level of a hierarchical scene may be affected by the abrupt appearance of a new object at the global level. Participants searched for a semi-disk target in an array of randomly oriented segmented disks ("pacmen"). On half the trials, a subset of the segmented disks induced a subjective square. On these critical trials, participants were significantly slower to respond to the presence of a local target even though the local features of the display were qualitatively identical across all conditions. This slowing was absent when outline pacmen were used (which do not induce subjective figures) and when the subjective square was perceptually old. When the participants' task was defined at the global level of the display, a new local element failed to capture attention, suggesting an asymmetry in the ability of objects at different levels of a hierarchical scene to capture attention. In a control experiment, a new local element captured attention, however, when the participants' task was defined at the local level, indicating that the local item was in principle capable of capturing attention. It is argued that global objects capture attention because they convey important information about the environment that is not available at the local level.
\end{abstract}

When a new perceptual object appears abruptly in a scene, it often captures visual attention (e.g., Yantis, 1993, 1996, 2000; Yantis \& Jonides, 1984). We have argued that new perceptual objects have high priority for visually guided behavior and that the visual system has therefore evolved to be "hard-wired" for the efficient detection of new objects (Yantis \& Hillstrom, 1994; Yantis \& Jonides, 1996). One striking exception to this finding is that a new object fails to capture attention when attention is focused in advance on another location in the scene (Theeuwes, 1991; Yantis \& Jonides, 1990). Again, this is adaptive: A deliberate strategy to focus attention should not be overridden by a stimulus-driven distraction.

Our aim in the present paper is to refine this tradeoff between an organism's intentions and hard-wired reflexes by investigating additional conditions under which a topdown attentional control strategy may be modulated by stimulus-driven attentional capture. Ignoring a bottomup signal is adaptive only when this signal does not add any ecologically significant information. As argued below, when a scene comprises several levels of hierarchical organization that are behaviorally relevant, it is not always

This research was supported by NIH Grant R01-MH43924 to S.Y. We thank Mike Albert, Angela Chung, Jennifer Cuzzocreo, Dan Feinberg, Dan Handwerker, Owen Johnson, Ben Kim, Phil Kim, Kim Larson, Tim Leary, Mick Smythwood, Tom Stergiou, Christine Vrettos, and Meredith Wells for assistance in running the experiments. We furthermore thank Anne Hillstrom, Kimron Shapiro, and two anonymous reviewers for their helpful comments on earlier drafts. Correspondence should be addressed to R. Rauschenberger, Department of Psychology, University of Arizona, Tucson, AZ 85721 or S. Yantis, Department of Psychology, Johns Hopkins University, Baltimore, MD 21218 (e-mail: rauschen@u.arizona.edu or yantis@jhu.edu). obvious that a stimulus-driven signal can and should be ignored, even when it conflicts with an organism's intentions.

What constitutes a perceptual object is not always clear (Palmer, 1977), and most objects can be described at more than one level of organization, from the most local to the most global, although typically only one level is relevant for perception at any given moment (Enns \& Kingstone, 1995; Kinchla \& Wolfe, 1979; Marr, 1982; Navon, 1977, 1981). For the purposes of the present paper, we will regard an object as global if its properties (e.g., shape, identity) are dependent on the existence and arrangement of more elementary objects, which will themselves be considered local relative to the global object.

Figure 1 depicts an example of a hierarchically composed stimulus, a "Navon letter" (see Navon, 1977). At the global level, this stimulus represents an uppercase letter $H$; at the local level, the stimulus is composed of a number of $E_{\mathrm{s}}$. It is important to recognize that the global interpretation of the Navon stimulus depends vitally on the spatial relationships among the local items and the object to which they give rise: A random arrangement of the $E$ s would destroy the global $H$ while leaving the $E$ s themselves intact. It is likewise important to note that the hierarchical nature of a stimulus is not based on scale or relative size (Navon, 1981): The Es composing the global $H$ could all be blown up to the size of the $H$; and, yet, they would remain local elements, provided that their relationship to the more global $H$ remained the same. This relationship holds only within the physical limits of the system (see Kinchla \& Wolfe, 1979; see also, however, Lamb \& Robertson, 1990). The distinction between sheer size and hierarchical relationship is vividly demonstrated by neuropsychological patients who exhibit impairments relat- 

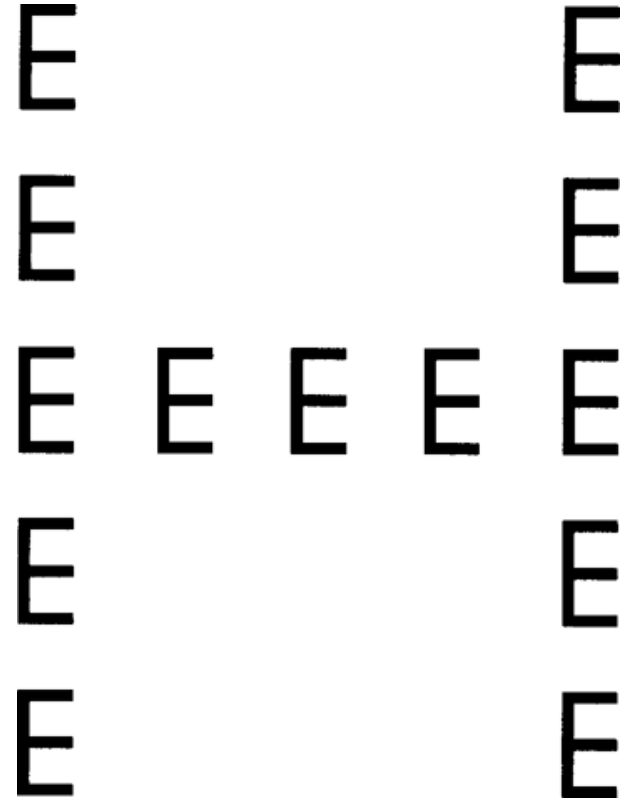

Figure 1. A Navon letter exemplifies a hierarchical stimulus: The global letter $H$ is composed of several local $E$ s.

ing to the organizational level of a stimulus without an attendant impairment related to scale (e.g., Marshall \& Halligan, 1995). Behavioral studies have shown as well that effects of hierarchy cannot simply be reduced to spatial frequency (e.g., Lamb \& Yund, 1996; Lamb, Yund, $\&$ Pond, 1999; but see also Robertson, 1999; for a more philosophical discussion of this issue, see Navon, 1981).

At the local level, the random arrangement of the $E \mathrm{~s}$, on the one hand, and their arrangement into a pattern that gives rise to the $H$, on the other, are completely equivalent. Within the local level, the $E$ s could be either independent objects or constituents of a more global object. Nature often capitalizes on this ambiguity in the form of camouflage: What, on the one hand, may be a harmless collection of disparate features may, on the other, very well belong to a well-camouflaged predator or prey. An example from Hillstrom and Yantis (1994) illustrates this point: The Geometridae moth found in northern Borneo often remains completely invisible when immobile because of its camouflaging coloration. Once it moves, however, the moth is immediately segregated from its background and becomes conspicuous. Motion serves here to create a new object representation at a global level of organization by affording an overarching organization into a coherent object, which in turn captures attention (see Figure 2a). However, motion alone, at the level of the individual camouflaging spots, is not sufficient to capture attention (Hillstrom \& Yantis, 1994). ${ }^{1}$

Given the ambiguous nature of local stimuli, it would be adaptive for an organism that has directed its attention to a local level of representation to remain sensitive to possibly important changes at a more global level. It would be adaptively sensible for the appearance of a new object at the global level to capture attention even when this appears to conflict with the organism's current behavioral goals: An animal that continues to attend to the individual spots of a camouflaged cheetah, even when they begin to cohere at a more global level, would quickly regret this evolutionary error.

\section{EXPERIMENT 1 Global Capture}

The present experiments were designed to test the hypothesis that new perceptual objects appearing abruptly at a global level of representation will capture attention even when participants are performing a task that is defined at a more local level. Kanizsa subjective figures (see Figure 2b) were chosen as stimuli for two reasons. First, such subjective figures represent possibly one of the strongest instances of an hierarchical object: Not only does a Kanizsa figure comprise both a local level (that of the inducing elements) and a global level (that of the induced object), but the global object exits only by virtue of the arrangement of local inducers. Second, this unique
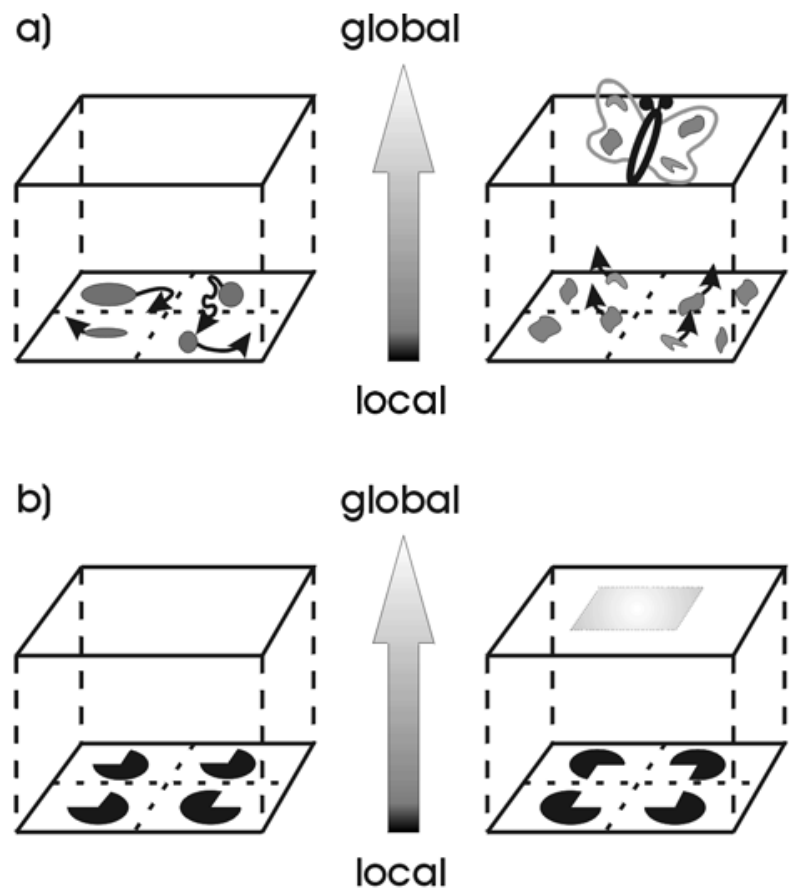

Figure 2. Illustrations of the local and global perceptual representations of a scene. (a) At a local level of organization, the two panels are indistinguishable: they consist of multiple moving elements. However, at a global level, the coherent motion of some of the local elements in the right panel reveals a new object. Inspection of the new object requires a redirection of attention to the global level of organization. (b) At a local level, the two arrangements of "pacmen" are identical. Only at a global level does it become apparent that the panel on the right induces a Kanizsa subjective figure, whereas the panel on the left does not. 
circumstance permits one to present local and global elements at different points in time, allowing for both perceptually old inducers and perceptually new subjective squares. This was achieved by premasking the local inducers. When the local items were finally unmasked, the subjective square had an abrupt onset, analogous to the case of the camouflaged predator that suddenly begins to move. If the visual system is indeed sensitive to global abrupt onsets even when attention is engaged locally, then the abrupt onset of the subjective square should capture attention even though participants were attending at the level of the local inducers.

\section{Method}

Participants. Fifteen Johns Hopkins University undergraduates (4 men, 11 women) participated in one 50-min session each in partial fulf illment of course credit. The mean age of the participants was 18.7 years, with a range of $18-21$ years. All participants were naive to the purpose of the study and reported normal or correctedto-normal vision.

Apparatus. The displays were generated on a 19-in. (48-cm) color monitor. The display was viewed from a distance of $54 \mathrm{~cm}$; a chinrest was used to maintain viewing distance. Responses were made on a custom button box. The experiment was conducted in a sound-attenuated room that was dimly lit with indirect incandescent lighting.

Stimuli. The stimuli consisted of four different types of segmented disks ("pacmen") that served as nontargets and two different types of semi-disk (see Figure 3). Each search display always contained one semi-disk and seven pacmen. The diameter of the disks was $1.5^{\circ}$ of visual angle. The luminance of the stimuli was $6.3 \mathrm{~cd} / \mathrm{m}^{2}$, and that of the background was $38.3 \mathrm{~cd} / \mathrm{m}^{2}$. For the visual search task, eight stimuli were arranged in a symmetric array centered on the screen around a fixation cross. The array measured $16.2^{\circ}$ wide $\times 6.5^{\circ}$ high. The stimuli were located on the vertices of two imaginary squares, one to the left and one to the right of fixation. The segmented disks could, if arranged appropriately, induce a subjective square in one of three positions: left, center, and right. The length of one side of the subjective square corresponded to the distance between the centers of its inducer disk segments; this distance was $5.0^{\circ}$. The peripheral subjective squares (left and right po- sitions) were included in the design because it is commonly assumed that attentional capture by abrupt onsets is most effective with peripheral stimulation (e.g., Müller \& Rabbitt, 1989; Nakayama \& Mackeben, 1989; Remington, Johnston, \& Yantis, 1992), perhaps due to the greater sensitivity of the transient channels in peripheral vision (Breitmeyer \& Ganz, 1976), which may mediate attentional capture by abrupt onsets (see Yantis, 2000).

Design. The participants completed five blocks of 96 trials each, following one practice block of 48 trials, resulting in a total of 528 trials per session. A $2 \times 2$ factorial design was used, with target (present, absent) and subjective square (present, absent) as factors. When the subjective square was present, it occurred in each of the three possible locations (left, center, right) equally often, and the target was a top- or bottom-truncated semi-disk equally often. The order of the trials within each block was randomly permuted.

Procedure. At the beginning of each trial, the target for that trial was presented in the center of the screen in isolation for $1,000 \mathrm{msec}$. This display was replaced by an array of eight complete disks and a fixation cross in the center of the screen. The complete disks functioned as placeholders similar to those in previous studies of attentional capture (e.g., Yantis \& Jonides, 1984; see also Todd \& Van Gelder, 1979). The placeholders and fixation cross were presented for 1,500 msec to allow ample time for these to be represented as perceptually old (see Yantis, 1993, 1996). After this time, seven pacman nontargets and one semi-disk were revealed by removing appropriate portions of the full placeholder disks; the fixation cross remained. On subjective square present trials, four of the seven pacmen induced a subjective square; precautions were taken to preclude the accidental generation of subjective contours on square absent trials. The participants were instructed to indicate whether or not the semi-disk in the search display was the target. The search display stayed on until a response was made.

The participants were instructed to look at the fixation cross throughout each trial. Eye movements were not monitored, since previous investigations have shown little effect of eye movement during tasks explicitly requiring covert shifts of attention, such as the present task (cf. Müller \& Rabbitt, 1989; Theeuwes, 1991; Yantis \& Jonides, 1990). The concept of covert attentional shifts was made clear to each participant prior to the beginning of the session, and the participants were told that eye movements would hinder their performance. There is little reason to suspect that the participants moved their eyes, because there were no cues to indicate the likely

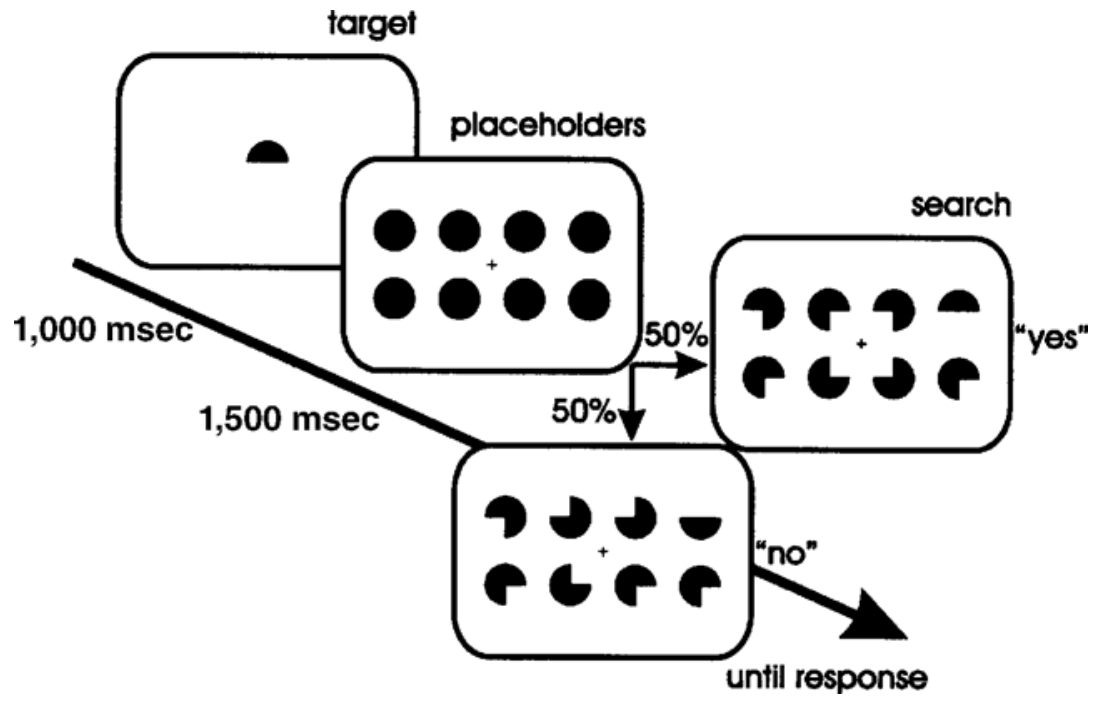

Figure 3. Sequence of events on a typical trial in Experiment 1. 
location of the target, and targets were equally likely on either side of fixation.

The participants were instructed to respond by pressing a button marked "Present" or a button marked "Absent." In case of an error, feedback was provided by two successive $150-$ msec $256-\mathrm{Hz}$ tones, and the participant was "penalized" with a timeout of $2 \mathrm{sec}$. Otherwise, the next trial began after an intertrial interval of $2 \mathrm{sec}$. Feedback was supplied at the end of each block by displaying the mean response time and the error rate, as well as the number of blocks remaining. If the participants made more than $5 \%$ errors on a given block, they were additionally cautioned to "please slow down and make fewer errors."

\section{Results}

The participants were slower to respond to the presence or the absence of the target when a subjective square was present $(817 \pm 37 \mathrm{msec})$ than when no square was present $(791 \pm 37 \mathrm{msec})$. The participants also were faster to respond when the target was present $(786 \pm 35 \mathrm{msec})$ than when it was absent $(860 \pm 34 \mathrm{msec})$. Overall, the participants made few errors $(2.7 \%)$. Error rates for each condition are shown in Table 1.

These trends were confirmed by statistical analysis. Correct response times (RTs) were subjected to a two-way within-participant analysis of variance (ANOVA), with target (absent, present) and square (absent, present) as factors. Both the main effect for target and the main effect for square were significant $[F(1,14)=12.54, p<.005$, and $F(1,14)=23.30, p<.0001$, respectively]. The interaction between the two factors was also significant $[F(1,14)=$ $28.47, p<.0001]$. This interaction was due to a larger effect of square presence on target-absent trials than on target-present trials. An identical ANOVA was performed on the error data. Only the main effect of target presence was significant $[F(1,14)=27.01, p<.0001]$.

The main effect of the subjective square presence was entirely due to the abrupt onset of the square in the central location. Although the participants were $74 \mathrm{msec}$ slower to issue a response when the central square was present $(866 \pm$ $38 \mathrm{msec})$ than when it was absent $(791 \pm 37 \mathrm{msec})$, the mean slowing for the peripheral squares $(792 \pm 34 \mathrm{msec}$, averaged across left and right) was only $1 \mathrm{msec}$. A twoway within-participant ANOVA, with target (absent, present) and square (absent, present left, present center, present right) as factors, confirmed these results. As before, both main effects were significant $[F(1,14)=18.28, p<$ .001 , for target; $F(3,42)=34.01, p<.0001$, for square], as was the interaction $[F(3,42)=9.67, p<.0001]$. However, planned contrasts revealed that the RTs for neither

Table 1

Error Rates (in Percentage) for Each Condition in Experiment 1

\begin{tabular}{lcccc}
\hline & \multicolumn{4}{c}{ Square } \\
\cline { 2 - 5 } & & Present \\
\cline { 2 - 5 } Target & Absent & Left & Center & Right \\
\hline Absent & 1.4 & 1.5 & 1.7 & 1.5 \\
Present & 3.9 & 2.3 & 5.3 & 4.2 \\
\hline
\end{tabular}

the left nor the right square locations differed significantly from the square absent RTs (both $F_{\mathrm{S}}<1$ ). By contrast, the difference between the square-present-center condition and the square-absent condition was highly significant $[F(1,14)=142.73, p<.0001]$.

An ANOVA of the error data mirrored the RT results. The effect of target was reliable $[F(1,14)=10.12, p<$ $.01]$, and the effect of square approached significance $[F(3,42)=2.76, p<.06]$. In planned contrasts, only the square-present-center condition differed reliably from the square-absent condition $[F(1,14)=5.19, p<.05]$. That is, the participants made significantly more errors when the square was present $(3.8 \%)$ than when no subjective square was present $(2.7 \%)$.

\section{Discussion}

In this experiment, the participants were required to find and identify a locally defined target as quickly as possible. At the local level, there were no differences among the displays - each of them contained the same types of stimuli (seven three-quarter disks and one semi-disk). The appearance of a subjective square on half of the trials was completely incidental to the arrangement of the nontargets. Nevertheless, the participants were slower to respond when the subjective square appeared in the center of the display than when there was no subjective square in the display. This increase in RT accompanying the onset of the square suggests that the square captured the participants' attention. The fact that only abrupt onsets in the central location had an effect, whereas those in the peripheral locations (left and right) did not, is consistent with the observation that the visibility of subjective squares diminishes with eccentricity (Grabowecky \& Treisman, 1989; Siegel \& Petry, 1991); apparently the subjective square at least needs to be represented as an object before it can capture attention.

However, an alternative account needs to be considered. ${ }^{2}$ It is possible that the participants used the subjective square as a spatial cue to the general region in which the target might be found: When the square appeared in a peripheral position, the participants could expect the target on the opposite side of the display. By contrast, when the square appeared centrally, the target could appear either on the left or on the right of fixation. The potential advantage conferred to the participants by using the subjective square as a cue could have given them an incentive to attend to the square deliberately. According to this account, when the square was located peripherally, the cost of deploying attention deliberately to the square "cue" would have been offset by a subsequent deployment to the region occupied by the target, yielding no net effect of square presence. In contrast, when the square was located centrally, it could have produced an observable cost, with no clear benefit, because the target could appear in either of two locations (to the right or to the left of the square).

We regard this explanation of our results as unlikely, given the results of the "square-new" condition in Experiment 3 (see below). To rule out this possibility more di- 
rectly, we ran a version of Experiment 1 in which the subjective square could appear only in the central location (thereby eliminating the informativeness of the square and any incentive to use it as a cue). The results of this experiment were quite comparable to those of Experiment 1: A significant 36-msec difference between square-present trials $(844 \pm 35 \mathrm{msec})$ and square-absent trials $(808 \pm$ $29 \mathrm{msec}$ ) remained $[F(1,12)=6.48, p<.03$, for targetpresent trials].

Although we have concluded that the abrupt appearance of a new global object captured attention in Experiment 1 and thereby slowed search for the local target, it is possible that some other aspect of the displays was actually responsible for this effect. Experiment 2 was designed to test one such possibility. The stimuli and design of Experiment 2 were nearly identical to those of Experiment 1 , except that the local elements were outline pacman shapes (see Figure 4), which do not induce subjective figures (Kanizsa, 1955/1987, 1976/1990; Meyer \& Fish, 1987; Meyer \& Garges, 1979; Pomerantz, Goldberg, Golder, \& Tetewsky, 1981). If the effects observed in Experiment 1 were due to the appearance of the subjective figure, and not an artifact of the particular arrangement of local items (e.g., symmetry in the arrangement of the inducing nontargets on square present trials), no such effects should be observed in Experiment 2.

\section{EXPERIMENT 2 Outline Inducers}

\section{Method}

Sixteen new participants ( 10 men, 6 women) took part in the second experiment in return for a small monetary sum or class credit. The mean age of the participants was 26.3 years, with a range of $18-41$ years. All participants reported normal or corrected-to-normal vision.

In addition to the use of outline stimuli instead of solid ones, some minor changes were made to the design, which were retained for all subsequent experiments. First, because Experiment 1 had confirmed the ineffectiveness of peripheral subjective squares, these were dropped from the design: When it was present, the "subjective square" arrangement always appeared in the center location. Second, the dimensions of the display were changed somewhat to make it more compact. The entire array now measured $13.8^{\circ} \times 5.9^{\circ}$; the sides of the subjective square measured $4.0^{\circ}$; and the segmented disks measured $2.0^{\circ}$. Finally, the duration of the placeholder display was reduced to $1,000 \mathrm{msec}$, which was still sufficient to render the local items perceptually old (e.g., Yantis \& Jonides, 1984) but reduced the duration of the experiment substantially. These changes in design are inconsequential for the comparison of the two experiments because the results of Experiment 1 were replicated not only in Experiment 3 below but also in another experiment reported elsewhere (Rauschenberger \& Yantis, 1998), both of which used the same design as Experiment 2.

The participants completed eight blocks of 64 trials each preceded by one practice block of 64 trials, resulting in a total number of 576 trials per session.

\section{Results and Discussion}

In contrast to Experiment 1, there was virtually no difference between the square-present $(888 \pm 60 \mathrm{msec})$ and square-absent $(891 \pm 61 \mathrm{msec})$ conditions. A two-way ANOVA of the correct RT data, with target (absent, present) and square (absent, present) as factors, yielded no significant main effects or interactions. An identical analysis of the error data likewise failed to reveal significant effects. Overall, the participants made $5.6 \%$ errors; error rates for each condition are shown in Table 2. These results show that the slowing observed in the squarepresent condition of Experiment 1 was due to the appearance of the subjective square, and not to some other confounding factor.

The possibility still remains, however, that, for some reason, the mere presence of the subjective square, and not its "newness" as a perceptual object, caused the effect in Experiment 1. For example, the subjective square might visually segregate the left and right halves of the display,

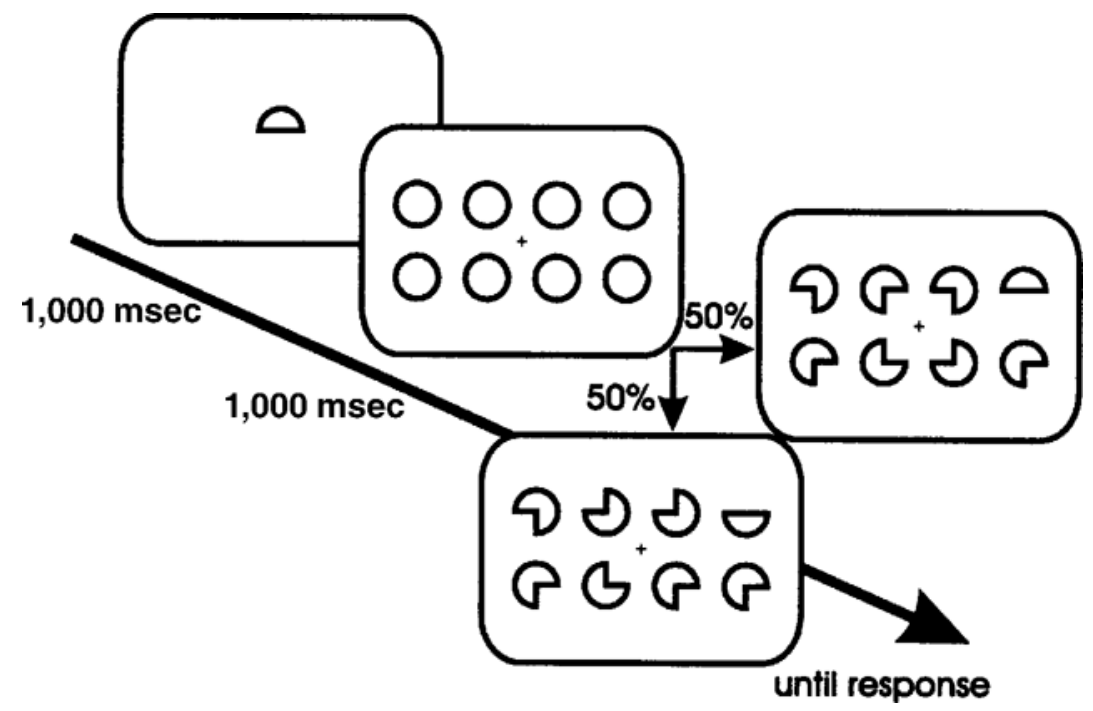

Figure 4. Sequence of events on a typical trial in Experiment 2. See text for details. 
Table 2

Error Rates (in Percentage) for Each Condition in Experiment 2

\begin{tabular}{ccc}
\hline & \multicolumn{2}{c}{ Square } \\
\cline { 2 - 3 } Target & Absent & Present \\
\hline Absent & 5.9 & 5.5 \\
Present & 5.3 & 5.6 \\
\hline
\end{tabular}

delaying a shift of attention from one side of the display to the other. This would undermine our claim that the abrupt onset of a new global object captures attention when attention is engaged locally. Experiment 3 therefore contrasted the effects of new subjective squares (as in Experiment 1) and perceptually old subjective squares that were presented simultaneously with the placeholders, $1,000 \mathrm{msec}$ before the targets were revealed. If our account is correct, then an old subjective square should have a much smaller effect on performance than a new one does.

\section{EXPERIMENT 3 Old and New Squares}

\section{Method}

Twenty-one new participants (5 men, 16 women), who received course credit for their participation, were recruited from the undergraduate subject pool at Johns Hopkins University. The mean age of the participants was 19.5 years, with a range of 18-21 years. All participants reported normal or corrected-to-normal vision. One participant's data were later discarded due to an error rate exceeding $10 \%$.

In this experiment, the subjective square was present on half the trials. When it was present, it was either perceptually old or (in separate blocks) perceptually new; the order of blocks was counterbalanced across participants. The square-new condition was identical to the square-present-ce nter condition in Experiment 1 (compare Figures 3 and 5). On square-old trials, the subjective square appeared at the onset of the premask display in the center of the display, whereas the peripherally located target and/or nontargets were unmasked 1,000 msec later (see Figure 5). On these trials, then, the subjective square was $1,000 \mathrm{msec}$ old by the time the participants could begin searching for the target. The participants completed six blocks of 64 trials following one practice block of 20 trials, resulting in a total of 404 trials per session.

\section{Results}

The comparisons of interest in this experiment are among the square-new, square-old, and square-absent conditions. The square-absent trials serve as a baseline against which performance on square-new and square-old trials may be compared. On square-new trials, RTs were slowed, relative to when there was no square present $(980 \pm$ $40 \mathrm{msec}$ vs. $961 \pm 38 \mathrm{msec}$ ), replicating the findings of Experiment $1 .{ }^{3}$ In contrast, responses were faster in the square-old condition $(909 \pm 38 \mathrm{msec})$ than in the squareabsent condition. Overall error rates were low, with a mean of $3.5 \%$ across participants. Error rates for each condition are shown in Table 3.
Both error rate and correct RT data were subjected to separate but identical within-participant ANOVAs, with target (absent, present) and square (square new, square old, square absent) as factors. For the RT data, the ANOVA revealed that target-present trials were significantly faster than target-absent trials $(1031 \pm 46 \mathrm{msec})[F(1,18)=$ $52.33, p<.0001]$ and that the three square conditions differed significantly from each other $[F(2,36)=18.62, p<$ $.0001]$. The interaction between target and square was not significant. Planned contrasts confirmed that the squarenew RTs were significantly slower than the square-absent RTs $[F(1,18)=8.45, p<.01]$ and that, by contrast, the square-old RTs were reliably faster than the square-absent $\operatorname{RTs}[F(1,18)=19.48, p<.0001]$. None of the effects were significant for the error data.

\section{Discussion}

Experiment 3 replicated Experiment 1 and, furthermore, ruled out the possibility that the mere presence of a surface intervening between the two sides of the display on which targets could occur was responsible for the ob-

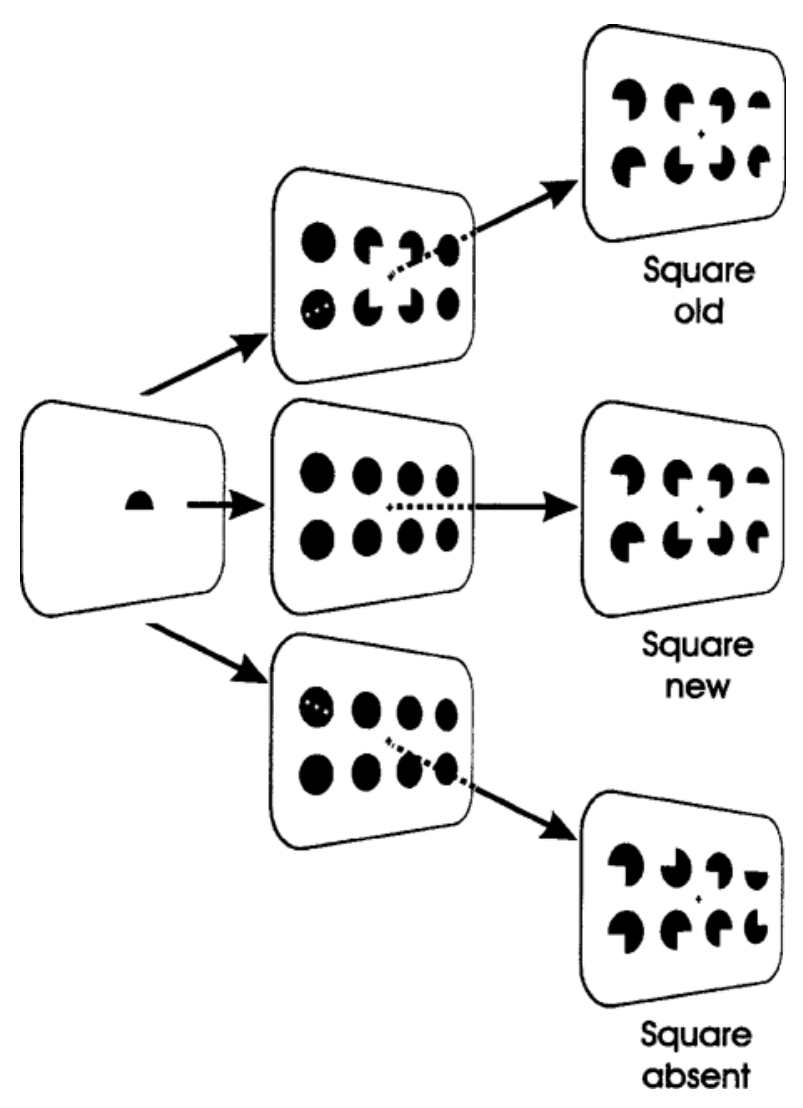

Figure 5. Sequence of events in Experiment 3. The subjective square could be perceptually old, perceptually new, as in Experiment 1 , or absent. On half of the trials, the square was absent; on the other half, the square was present. Of the present trials, half were square-new trials, and the other half were square-absent trials. 
Table 3

Error Rates (in Percentage) for Each Condition in Experiment 3

\begin{tabular}{cccc}
\hline & \multicolumn{3}{c}{ Square } \\
\cline { 2 - 4 } Target & Absent & Old & New \\
\hline Absent & 3.5 & 3.3 & 4.0 \\
Present & 3.8 & 3.6 & 3.0 \\
\hline
\end{tabular}

served slowing of RTs. The finding that only a new perceptual object interferes with target detection suggests that the abrupt appearance of the subjective square captured the participants' attention away from their search task.

It is further noteworthy that the abrupt onset of the subjective square captured the participants' attention, because the target never appeared in the central four positions that contained the square-inducing items on squarepresent trials, and this should have rendered those locations completely task irrelevant. The fact that their arrangement on square-new trials nevertheless slowed the participants' RTs can only be explained by the fact that square-present and square-absent trials differed at a global level. This difference at the global level was discussed in the introduction as the distinction between a random arrangement of disparate items and a set of local items that form the basis for a more global object.

The observed difference between square-new and square-old conditions cannot be attributed to the fact that the conditions were run in separate blocks, potentially giving the participants the opportunity to adopt a strategy appropriate for trials on which the subjective square appeared long before the target was revealed. A version of the experiment with mixed trials reported elsewhere (Rauschenberger \& Yantis, 1998) produced qualitatively identical results, ruling out any strategic account.

\section{EXPERIMENT 4 Global-Local Asymmetry}

The conclusion up to this point is that new objects at the global level of a hierarchically structured display capture attention when attention is engaged at a more local level, even when the global level has no immediate behavioral relevance. This ability of global objects to capture attention implicates some default sensitivity to the appearance of new global objects, which may be indistinguishable at the local level from a random arrangement of features. By comparison, however, there is no reason to assume that new local objects have the same effect when attention is directed to the global level: At the global level, a representation of the entire display, including its local constituents, is readily available, although perhaps at the cost of detail (see Bravo \& Nakayama, 1992; Nakayama, 1990). A small change in the detail of a scene will seldom have serious repercussions when the global level of representation is behaviorally relevant. (Whether a cheetah has one spot more or less makes no difference once the cheetah has been detected.) Consequently, one might expect to find an asymmetry in the ability of global and local new objects to capture attention.

Experiment 4 examined the ability of new local objects to capture attention when attention is engaged more globally. The participants were given a task defined at the global level of the display, and the attentional consequences of the abrupt appearance of a local element were assessed. The global object was again an illusory object (in this case, an illusory triangle rather than a square). The participants' task was to indicate the direction in which the triangle was pointing.

\section{Method}

Eighteen new participants ( 9 men, 9 women) took part in the experiment in return for credit (or pay in one case). The mean age of the participants was 20.9 years, with a range of $17-44$ years. One participant's data were lost due to computer failure.

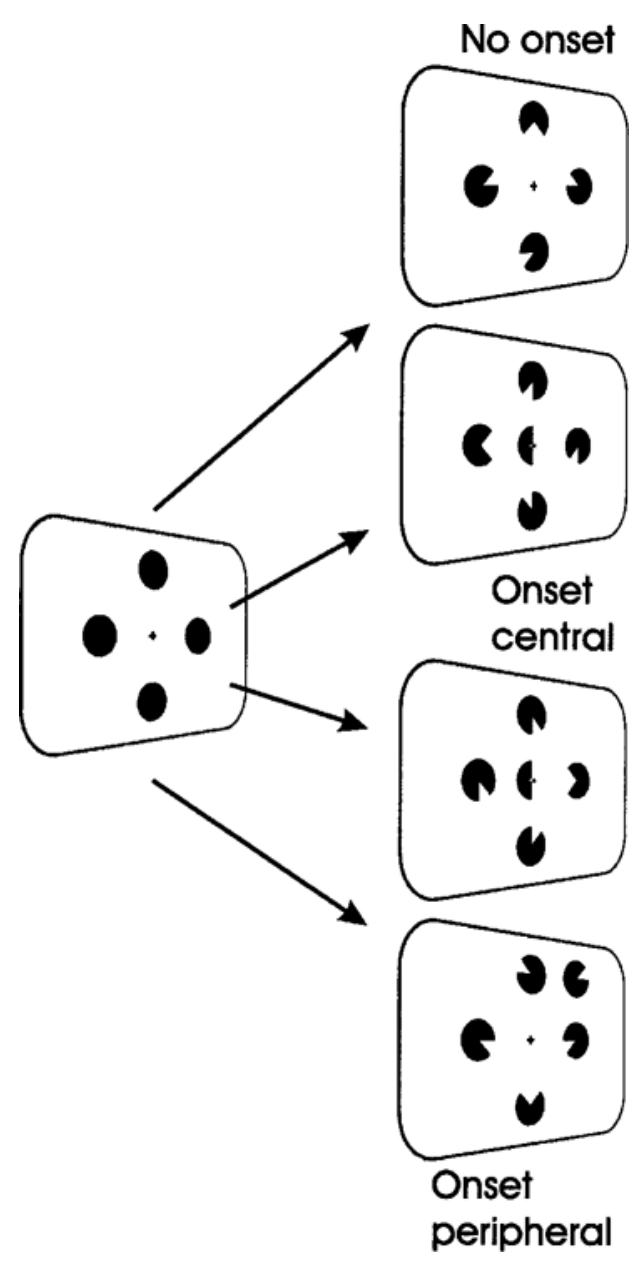

Figure 6. Sequence of events in Experiment 4. The participants' task was to indicate the direction in which the subjective triangle was pointing. On half of the trials, a local element could have an abrupt onset either in one of the peripheral positions or in the central position. 
The present experiment used solid pacman and semi-disk stimuli, as in Experiment 1, with the exception that the segmented disks had either $90^{\circ}$ or $45^{\circ}$ segments removed, allowing them to induce an illusory triangle rather than a square (see Figure 6). The inducers were no longer arranged in a $2 \times 4$ grid but were arranged in a $3 \times 3$ grid, in which four positions always contained a disk; these were the middle position in the top row, the two outer positions in the middle row, and the middle position in the bottom row. These four elements, three of which participated in the induction of the illusory triangle, were positioned on the vertices of a (virtual) rhombus. The horizontal and vertical distance between the centers of the four elements subtended $3.94^{\circ}$ of visual angle. The illusory triangle could point left, right, up, or down. The angle at the apex of the triangle was $90^{\circ}$, and those at the base were $45^{\circ}$. The length of the base subtended $3.9^{\circ}$, corresponding to the horizontal or vertical separation of the inducers; the height of the triangle subtended $2.0^{\circ}$. The luminance of the stimuli and the background remained the same as in the previous experiments. The diameter of the disks subtended $2.0^{\circ}$ of visual angle.

The participants completed a total of 768 trials over three blocks of 256 trials each, preceded by a practice block of 32 trials. The practice trials did not contain any experimental manipulation (i.e., they did not have any abrupt onsets). They were merely intended to give the participants experience with the task and a chance to familiarize themselves with the mapping of the responses onto the response buttons. Of the experimental trials, half had an onset of a disk segment in one of the positions not occupied by the four pacmen always present in the display, and half did not. Of the onsets, half occurred in one of four peripheral locations with equal probability, and the other half occurred in the central position. The central-onset item was always a semi-disk whose straight edge coincided with the base of the illusory triangle, and which either faced into or out of the illusory triangle (see Figure 6). When the semi-disk faced into the triangle, it appeared to cover up a small portion of the triangle; when it faced out of the triangle, due to amodal completion, it appeared as a whole disk that was half covered by the triangle.

\section{Results and Discussion}

The mean RT difference between the onset and no-onset conditions was $2 \mathrm{msec}[t(16)=0.23$, n.s.], and the mean difference in error rates was $0.18 \%[t(16)=0.97$, n.s. $]$. The difference (in both RT and error rates) between the noonset condition ( $696 \pm 47 \mathrm{msec} ; 1.77 \%)$, the center-onset condition (686 $\pm 43 \mathrm{msec} ; 1.44 \%)$, and the peripheralonset condition (702 $\pm 48 \mathrm{msec} ; 1.70 \%)$ was negligible and did not reach statistical significance $(F<1)$.

The peripheral onset might have been expected to have a larger effect than the central onset, on the basis of the assumption that peripheral onsets more effectively capture attention than central onsets (e.g., Müller \& Rabbitt, 1989; Nakayama \& Mackeben, 1989; Remington et al., 1992). Apparently, however, this was not the case: A planned contrast between center-onset and peripheral-onset conditions revealed no difference ( $F<1$, for both RT and error rates). The center onset facing into the triangle might have been expected to yield slower RTs than the center onset facing out of the triangle, because the latter onset appears to occur underneath the object to be attended (due to amodal completion), whereas the former not only appears to occur above the attended object but furthermore alters the appearance of this object. This reasoning was the rationale for including both conditions as part of the design for this experiment. However, statistical analysis proved the $16 \mathrm{msec}$ difference in $\mathrm{RT}$, as well as the
$0.25 \%$ error rate difference, between the two conditions to be nonsignificant $[t(16)=1.04$, n.s., and $t(16)=0.75$, n.s., respectively].

The abrupt appearance of a new local object had no reliable effect on the participants' performance when their task required discrimination at the global level of the display. Indeed, it would have been surprising if a change to irrelevant detail of the display would have caused an interruption of the participants' performance if their task did not require them to be interested in detail. This failure to capture attention stands in contrast to the ability of irrelevant global onsets in Experiments 1 and 3 to capture attention away from the more local level, revealing an asymmetry in the ability of new objects to capture attention across levels of hierarchical representation. Such an asymmetry is well known from the literature on the "globalprecedence effect" (see Navon, 1977, 1981; Paquet, 1992; Paquet \& Merikle, 1988; Stoffer, 1994). Indeed, Stoffer (1994) argues that this asymmetry may be due to the potential of the global stimulus to capture attention at the expense of the local stimuli, as is suggested here.

These results appear to stand in contrast to those of Hillstrom and Yantis (1994), in whose Experiment 2 the abrupt onset of a local element in a Navon letter did capture attention even though participants were engaged in a task defined at the global level of the stimulus. This difference in results may be attributed to the fact that the abruptly onset local element in Hillstrom and Yantis's experiment was a constituent part of the global shape; this global shape owed its very existence to the appearance of the local item. The appearance of the local item precipitated the appearance of a new global object, its effect thereby penetrating through to the global level of the display. By contrast, in our experiment, the abruptly onset item appeared at the local level of the display, but it was not itself part of the subjective figure inducing elements. In fact, the global shape antedated the appearance of the local item in its existence as a perceptual object. In our experiment, therefore, the abrupt onset of an item at the local level of the display did not have any implications for the global interpretation of the display. The difference in results between Hillstrom and Yantis's experiment and ours is entirely in line with our model (see the introduction).

The possibility remains, however, that the items used in Experiment 4 were simply ineffective in capturing attention, irrespective of the level at which attention was engaged. Experiment 5 examined whether the local element used in Experiment 4 was capable of capturing attention when the participants' attention was engaged locally (as defined in the introduction). Experiment 5 was therefore comparable to attentional capture experiments in the literature (e.g., Yantis \& Jonides, 1984), with the exception that the abrupt onset item in this experiment was never the target. This slight modification of the traditional attentional capture paradigm, in which the abrupt onset item is the target on $1 / n$ of the trails (where $n$ is the number of display items), was necessary because the new object in Experiments 1, 3, and 4 was also never the target. 


\section{EXPERIMENT 5 \\ Local Capture}

\section{Method}

Thirteen new participants ( 5 men, 8 women) were recruited from Johns Hopkins University undergraduate subject pool. The mean age of the participants was 19.7 years, with a range of 17-21 years.

The stimuli in Experiment 5 were similar to those in Experiment 3. The target, which was present on half of the trials and absent otherwise, was a semi-disk, as before, and pacmen served as nontargets. In the present experiment, however, these pacmen never induced an illusory object. Instead, one of the pacmen had an abrupt onset on half of the trials. The semi-disk and three-quarter disk segments were arranged in the same eight positions used in Experiments 2 and 3.

Five different display set sizes $(4,5,6,7$, and 8 items/display, respectively) were used; each occurred equally often. We varied set size because displays with an onset always contain one item more than displays without an onset, which complicates the comparison of search times and error rates. If one equates the number of items in the final display, the number of items in the premask display predicts whether or not a given trial will have an onset. By varying set size, it is possible to make the premask display ambiguous, because it can lead to either a final display with the same number of items (noonset trial) or a display with one additional item (onset trial). The trials that are then used for comparison are those with the same number of items in the final display. Note that the smallest set size does not permit such a comparison, because it is never produced by adding an item to a still smaller setsize. Displays with Set Size 4 were merely included in this experiment to render premask displays with four items ambiguous; data from these trials were discarded. To reduce the proportion of trials that needed to be discarded, a fairly large number of set sizes was used; with five different set sizes, the Set Size 4 trials represent only one ninth of the total number of trials. To reduce the number of trials discarded even further, Set Size 8 trials were retained for analysis. Eight items per display was the largest number of items possible with our displays; Set Size 8 was therefore predictable in the sense that eight premasks would always lead to a no-onset display. Eliminating these trials would have meant also discarding trials on which seven premasks led to a final display of eight items (onset trials for Set Size 8).

\section{Results and Discussion}

As expected, and contrary to Experiment 4 , the abrupt appearance of a local item interfered with the participants' responses in this experiment. The participants were slower to respond on trials with a new local item $(948 \pm 48 \mathrm{msec})$ than on trials without $(933 \pm 47 \mathrm{msec})^{4}[t(12)=2.77, p<$ $.01]$. The participants made slightly more errors in the noonset condition (3.4\%) than in the onset condition (3.3\%) $[t(12)=0.18$, n.s. $]$. A three-way within-participant ANOVA of the correct RT data, with target (absent, present), onset (absent, present), and set size $(5,6,7,8)$ as factors, revealed significant main effects for target $[F(1,12)=$ $51.58, p<.0001]$, onset $[F(1,12)=7.61, p<.02]$, and set size $[F(1,12)=12.94, p<.0001]$, but no significant interaction (all $F_{\mathrm{s}}<1$ ).

This result shows that, although new local items fail to capture attention away from the global level of a display, they are potent enough to capture attention when it is engaged at the local level. This ability requires further commentary, because the onset item in this experiment captured attention even though it was itself never the target.
On the one hand, the onset item shared significant features with the target, making it at least as good a candidate for the target as any of the other items. (Note that this was not the case for the attention-capturing subjective square in Experiments 1 and 3, however.) On the other hand, the participants should have been able to adopt a control setting that excludes any abrupt onset item (Folk \& Remington, 1999; Folk, Remington, \& Johnston, 1992). Participants, for example, are capable of suppressing an involuntary shift of attention to an onset item that is not the target when they know the target position in advance (Yantis \& Jonides, 1990). In the latter case, however, participants had positional certainty about the location of the target, whereas, in the present experiment, they had no advance knowledge of either the target position or the location of the onset item. More comparable are the experiments reported by Folk and Remington (1999), in which an abrupt onset failed to interfere with target detection when participants were looking for a color-defined target. Our findings, then, stand in opposition to those of Folk and Remington (1999). A discussion of this apparent discrepancy is beyond the scope of this article.

\section{GENERAL DISCUSSION}

The findings reported here suggest that the visual system is sensitive to abrupt changes that occur at a level more global than the one at which attention is currently engaged. Kanizsa subjective figures served as global items, and the inducers served as local items. The task required the participants to direct attention to the local level, within which none of the displays differed qualitatively from each other. When a subset of the local items induced a subjective square that was only available at a more global level, RTs were significantly slowed (Experiment 1 ). When outline "inducers" were used instead of solid ones, the effect disappeared (Experiment 2). Furthermore, the occurrence of attentional capture depended on the subjective square's being new, and not its mere presence (Experiment 3). The ability of a new object to capture attention across different levels of hierarchical representation appears to be asymmetrical: New global objects can capture attention away from a local level, whereas the reverse is not true (Experiment 4). A modified replication of the typical attentional capture paradigm established that local items that could not divert attention from the global level nonetheless exerted an effect at the local level (Experiment 5).

In Experiments 1 and 3, the attention-capturing subjective square was never part of the participants' attentional set and was never itself the target. This speaks to two criticisms of the claim that new perceptual objects capture attention in a purely stimulus-driven fashion. First, Folk, Remington, and Johnston $(1992,1993)$ raised the possibility that attentional capture is never entirely automatic but is contingent on the congruence of (bottom-up) stimulus features and (top-down) attentional set. In the present experiments, the participants could not sensibly form 
a set for the attention-capturing object (the subjective square) because it was never the target, nor did it convey any information about the target.

The experiments also undermine an account of attentional capture based on forward masking of the no-onset items made by Gibson (1996a, 1996b; see also Yantis \& Jonides, 1996). Gibson suggested that onset targets enjoy an attentional advantage over no-onset items because the latter are perceptually degraded (relative to onsets) due to forward masking by the figure-eight placeholders that precede them, and this in turn slows RT when the target happens to be a no-onset item. In the present experiments, all target and nontarget items were equally premasked in all conditions; any difference in performance cannot have been due to a difference in the perceptual quality of the target. Because the illusory square depended on the arrangement of pacmen, there was no asymmetry in the perceptual quality of the onset and no-onset items. Finally, in the present experiments, attentional capture was manifested as an impairment in performance, not as a benefit for onset targets.

The experiments speak to another relevant issue. There is ample evidence to suggest that new objects capture attention independent of the luminance transients that typically accompany the appearance of an object (e.g., Enns, Austen, Di Lollo, Rauschenberger, \& Yantis, in press; Enns, Yantis, \& Di Lollo, 1998; Yantis \& Hillstrom, 1994). Recently, this position has been called into question by findings that luminance transients may contribute substantially to attentional capture after all (Gellatly, Cole, \& Blurton, 1999). These competing hypotheses have been referred to as the new-object explanation and the luminanceincrement explanation, respectively (Yantis \& Hillstrom, 1994). The results of the present experiments support the new-object account. First, the abrupt onset of the subjective square that captured attention was not accompanied by any luminance transients other than those associated with the removal of one-quarter disk segments from the placeholder disks (which were equal both across the entire display and across conditions). Indeed, one of the advantages of using a subjective square to examine attentional capture is that its onset is not confounded with luminance transients in the sense that the abrupt onset of luminancedefined objects is. One could argue that subjective contours are represented explicitly in the brain (see von der Heydt, Peterhans, \& Baumgartner, 1984) and that the visual system therefore "sees" a luminance boundary at some level of processing in the brain. Furthermore, there is psychophysical evidence that subjective squares appear to be slightly brighter than their backgrounds (e.g., Halpern, 1987). However, in this case, one would have to argue that attention is captured by an inferred feature, and no longer by a property of the physical stimulus itself, blurring the boundaries between the new-object account and the more low-level luminance-increment explanation. Several lines of research suggest that the perceived brightness enhancement associated with a subjective figure is dissociable from the low-level properties of the subjective contours bounding the figure (see Dresp, 1992; Dresp, Lorenceau, \& Bonnet, 1989; Rieger \& Gegenfurtner, 1998). In fact, illusory figures can be observed without attendant brightness enhancement (see, e.g., Parks, 1980; Prazdny, 1983), and cases of perceived brightness are thought to be the result of a more high-level filling-in of the subjective figure (e.g., Dresp, 1992; Rieger \& Gegenfurtner, 1998; Watanabe \& Oyama, 1987). Luminance-increment-based capture via perceived brightness of the subjective square is therefore not a parsimonious account of our findings.

The present experiments show that the visual system is sensitive to global implications of seemingly insignificant differences in the arrangement of local features even when attention is deliberately directed at a local level of organization. This sensitivity prevents an organism from "losing itself" in the details of a scene while important information becomes available at a global level that would otherwise be missed. A picture of the visual system emerges that allows for far greater flexibility than the traditional dichotomy of exogenous and endogenous mechanisms admits: In general, abrupt onsets of new objects draw attention to themselves because they represent important events in the environment (see Yantis, 1993, 1996). When top-down goals conflict with these stimulusdriven operations, however, it is possible for an organism to exert top-down control over its attentional mechanisms, especially when the abrupt onsets do not provide any useful information (e.g., Experiment 4 of the present paper; Theeuwes, 1991; Warner, Joula, \& Koshino, 1990; Yantis \& Jonides, 1990). Finally, however, when a certain class of bottom-up activation (i.e., global abrupt onsets) signals unattended events of high behavioral significance, goal-directed attentional mechanisms will again yield to stimulus-driven factors.

\section{REFERENCES}

Bravo, M. J., \& NaKay Ama, K. (1992). The role of attention in different visual-search tasks. Perception \& Psychophysics, 51, 465-472.

Breitmeyer, B. G., \& Ganz, L. (1976). Implications of sustained and transient channels for theories of visual pattern masking, saccadic suppression, and information processing. Psychological Review, 83, 1-36.

DRESP, B. (1992). Local brightness mechanisms sketch out surfaces but do not fill them in: Psychophysical evidence in the Kanizsa square. Perception \& Psychophysics, 52, 562-570.

Dresp, B., Lorenceau, J., \& Bonnet, C. (1989). Apparent brightness enhancement in the Kanizsa square with and without illusory contour formation. Perception, 19, 483-489.

Enns, J. T., Austen, E. L., Di Lollo, V., Rauschenberger, R, \& YanTIS, S. (in press). New objects dominate luminance transients in attentional capture. Journal of Experimental Psychology: Human Perception \& Performance.

Enns, J. T., \& Kingstone, A. (1995). Access to global and local properties in visual search for compound stimuli. Psychological Science, 6 , 283-291.

Enns, J. T., Yantis, S., \& Di Lollo, V. (1998, May). Luminance transients capture attention, but only in new display locations. Poster session presented at the annual meeting of the Association for Research in Vision and Ophthalmology, Ft. Lauderdale, FL.

Folk, C. L., \& Remington, R. W. (1999). Can new objects override attentional control settings? Perception \& Psychophysics, 61, 727-739.

Folk, C. L., Remington, R. W., \& Johnston, J. C. (1992). Involuntary covert orienting is contingent on attentional control settings. Journal 
of Experimental Psychology: Human Perception \& Performance, 18, 1030-1044.

Folk, C. L., Remington, R. W., \& Johnston, J. C. (1993). Contingent attentional capture: A reply to Yantis (1993). Journal of Experimental Psychology: Human Perception \& Performance, 19, 682-685.

Gellatly, A., Cole, G., \& Blurton, A. (1999). Do equiluminant object onsets capture visual attention? Journal of Experimental Psychology: Human Perception \& Performance, 25, 1609-1624.

GiBson, B. S. (1996a). The masking account of attentional capture: A reply to Yantis and Jonides (1996). Journal of Experimental Psychology: Human Perception \& Performance, 22, 1514-1520.

GiBson, B. S. (1996b). Visual quality and attentional capture: A challenge to the special role of abrupt onsets. Journal of Experimental Psychology: Human Perception \& Performance, 22, 1496-1504.

Grabowecky, M., \& Treisman, A. M. (1989, May). Attention and fixation in subjective contour perception. Poster session presented at the annual meeting of the Association for Research in Vision and Ophthalmology, Saratoga, FL.

Halpern, D. F. (1987). The functional equivalence of objective and illusory brightness enhancement. In S. J. Petri \& G. E. Meyer (Eds.), The perception of illusory contours (pp. 171-175). New York: SpringerVerlag.

Hillstrom, A. P., \& YAntis, S. (1994). Visual motion and attentional capture. Perception \& Psychophysics, 55, 399-411.

KANIZSA, G. (1987). Quasi-perceptual margins in homogeneously stimulated fields (W. Gerbino, Trans.). In S. J. Petri \& G. E. Meyer (Eds.), The perception of illusory contours (pp. 40-49). New York: SpringerVerlag. (Original work published 1955)

KanIzSA, G. (1990). Subjective contours. In I. Rock (Ed.), The perceptual world: Readings from Scientific American (pp. 155-163). New York: W. H. Freeman. (Original work published 1976)

Kinchla, R. A., \& WoLfe, J. M. (1979). The order of visual processing: "Top-down," "bottom-up," or “middle-out." Perception \& Psychophysics, 25, 225-231.

LAMB, M. R., \& RoberTson, L. C. (1990). The effect of visual angle on global and local reaction times depends on the set of visual angles presented. Perception \& Psychophysics, 47, 489-496.

LAMB, M. R. \& YUND, E. W. (1996). Spatial frequency and interference between global and local levels of structure. Visual Cognition, 3, 193219.

LAmb, M. R., Yund, E. W., \& Pond, H. M. (1999). Is attentional selection to different levels of hierarchical structure based on spatial frequency? Journal of Experimental Psychology: Human Perception \& Performance, 128, 88-94.

Marr, D. (1982). Vision. San Francisco: W. H. Freeman.

Marshall, J. C., \& Halligan, P. W. (1995). Seeing the forest but only half the trees? Nature, 373, 521-523.

Meyer, G. E., \& Fish, D. (1987). Illusory contours, texture segregation, and a configural inferiority effect. In S. J. Petri \& G. E. Meyer (Eds.), The perception of illusory contours (pp. 224-234). New York: SpringerVerlag.

Meyer, G. E., \& Garges, C. (1979). Subjective contours and the Poggendorff illusion. Perception \& Psychophysics, 26, 302-304.

Müller, H. J., \& RabBitT, P. M. A. (1989). Reflexive and voluntary orienting of visual attention: Time course of activation and resistance to interruption. Journal of Experimental Psychology: Human Perception \& Performance, 15, 315-330.

NaKaYAma, K. (1990). The iconic bottleneck and the tenuous link between early visual processing and perception. In C. Blakemore (Ed.), Vision: Coding and efficiency (pp. 411-422). New York: Cambridge University Press.

Nakayama, K., \& Mackeben, M. (1989). Sustained and transient components of focal visual attention. Vision Research, 29, 16311647.

Navon, D. (1977). Forest before trees: The precedence of global features in visual perception. Cognitive Psychology, 9, 353-383.

NAVON, D. (1981). The forest revisited: More on global precedence. Psychological Research, 43, 1-32.

PALMER, S. E. (1977). Hierarchical structure in perceptual representation. Cognitive Psychology, 9, 441-474.

PAQUET, L. (1992). Global and local processing in nonattended objects:
A failure to induce local processing dominance. Journal of Experimental Psychology: Human Perception \& Performance, 18, 512-529.

Paquet, L., \& Merikle, P. M. (1988). Global precedence in attended and nonattended objects. Journal of Experimental Psychology: Human Perception \& Performance, 14, 89-100.

Parks, T. E. (1980). [Letter to the Editor]. Perception, 9, 723.

Pomerantz, J. R., Goldberg, D. M., Golder, P. S., \& Tetewsky, S. (1981). Subjective contours can facilitate performance in a reactiontime task. Perception \& Psychophysics, 29, 605-611.

PrazDNy, K. (1983). Illusory contours are not caused by simultaneous brightness contrast. Perception \& Psychophysics, 34, 403-404.

RAUschenberger, R., \& YANTIS, S. (1998, May). Attentional capture through levels of representation. Poster session presented at the annual meeting of the Association for Research in Vision and Ophthalmology, Ft. Lauderdale, FL.

Remington, R. W., Johnston, J. C., \& Yantis, S. (1992). Involuntary attentional capture by abrupt onsets. Perception \& Psychophysics, 51, 279-290.

Rieger, J., \& Gegenfurtner, K. R. (1998). Contrast sensitivity and appearance in briefly presented illusory figures. Spatial Vision, 12, 329344.

Robertson, L. C. (1999). Spatial frequencies as a medium for guiding attention: Comment on Lamb, Yund, and Pond. Journal of Experimental Psychology: General, 128, 95-98.

Siegel, S., \& Petry, S. (1991). Evidence for independent processing of subjective contour brightness and sharpness. Perception, 20, 233241.

Stoffer, T. H. (1994). Attentional zooming and the global-dominance phenomenon: Effects of level-specific cueing and abrupt visual onset. Psychological Research, 56, 83-98.

TheEUwes, J. (1991). Exogenous and endogenous control of attention: The effect of visual onsets and offsets. Perception \& Psychophysics, 49, 83-90.

Todd, J. T., \& VAN GELder, P. (1979). Implications of a transientsustained dichotomy for the measurement of human performance. Journal of Experimental Psychology: Human Perception \& Performance, 5, 625-636.

von der Heydt, R., Peterhans, E., \& Baumgartner, G. (1984). Illusory contours and cortical neuron responses. Science, 224, 1260 1262 .

WARner, C. B., Juola, J. F., \& Koshino, H. (1990). Voluntary allocation versus automatic capture of visual attention. Perception \& Psychophysics, 48, 243-251.

Watanabe, T., \& Oyama, T. (1987). Are illusory contours a cause or a consequence of apparent differences in brightness and depth in the Kanizsa square? Perception, 17, 513-521.

YAnTIS, S. (1993). Stimulus-driven attentional capture. Current Directions in Psychological Science, 2, 156-161.

YANTIS, S. (1996). Attentional capture in vision. In A. F. Kramer, M. G. H. Coles, \& G. D. Logan (Eds.), Converging operations in the study of selective attention (pp. 45-76). Washington, DC: APA.

YANTIS, S. (2000). Goal-directed and stimulus-driven determinants of attentional control. In S. Monsell \& J. Driver (Eds.), Attention and performance XVIII (pp. 73-103). Cambridge, MA: MIT Press.

YANTIS, S., \& Hillstrom, A. (1994). Stimulus-driven attentional capture: Evidence from equiluminant visual objects. Journal of Experimental Psychology: Human Perception \& Performance, 20, 95-107.

YANTIS, S., \& Jonides, J. (1984). Abrupt visual onsets and selective attention: Evidence from visual search. Journal of Experimental Psychology: Human Perception \& Performance, 10, 601-621.

YANTIS, S., \& Jonides, J. (1990). Abrupt visual onsets and selective attention: Voluntary versus automatic allocation. Journal of Experimental Psychology: Human Perception \& Performance, 16, 121-134.

YANTIS, S., \& JoNidES, J. (1996). Attentional capture by abrupt onsets: New perceptual objects or visual masking? Journal of Experimental Psychology: Human Perception \& Performance, 22, 1505-1513.

\section{NOTES}

1. Hillstrom and Yantis's (1994) Experiment 2 did show that motion of a local element captures attention when it segregates this element from 
its background and thereby causes a new object file to be opened. However, motion per se, when it is not accompanied by the creation of a new object file, does not capture attention (Hillstrom \& Yantis, 1994, Experiment 3, "old motion" condition).

2. We thank Anne Hillstrom for suggesting this alternative account.

3. This difference in RT represents a reduction from the effect observed in Experiment 1. This decrease in effect size may, however, be explained by the high spatial certainty associated with the onset of the subjective square in this experiment (center position only), as compared with Experiment 1 (left, center, and right positions).

4. The correct RT data were trimmed by removing all trials with response times of 3,000 msec or more. Trimming the data in this way seemed the most unbiased way of removing trials with excessively long
RTs, which, for some reason, were fairly frequent in this particular experiment (45 trials total across all participants). These trials occurred almost exclusively in response to the beginning of a block or immediately following an error trial. Because outliers had not been removed in any of the previous experiments (they occurred very infrequently), we reran the analyses of these experiments after the removal of outliers (following the same criteria as used in Experiment 5) as a precautionary measure. The results were qualitatively and statistically identical to those obtained without the removal of outliers.

(Manuscript received March 14, 2000; revision accepted for publication March 20, 2001.) 